\title{
Author Self-Citation in the Turkish Otorhinolaryngology Literature
}

\author{
Original Investigation $>$ (1) Ali Bayram \\ Department of Otorhinolaryngology, Kayseri City Training and Research Hospital, Kayseri, Turkey
}

ORCID ID of the authors:

A.B. 0000-0002-0061-1755

Cite this article as: Bayram A. Author SelfCitation in the Turkish Otorhinolaryngology Literature. Turk Arch Otorhinolaryngol 2021; 59(3):210-4.

\section{Corresponding Author:}

Ali Bayram; dralibayram@gmail.com

Received Date: 22.05 .2021 Accepted Date: 04.07.2021

Content of this journal is licensed under a Creative Commons Attribution 4.0 International License. Available online at www.turkarchotolaryngol.net

\section{(c) (i) \$}

DOI: 10.4274/tao.2021.2021-5-16

Objective: To evaluate the prevalence and other characteristics of author self-citations in six Turkey-originated general otorhinolaryngology (ORL) journals of Turkish ORL literature.

Methods: A total of 970 articles published in six Turkey-originated general ORL journals (ENT Updates, Journal of Ear Nose Throat and Head Neck Surgery, KBB-Forum, Praxis of Otorhinolaryngology, The Turkish Journal of Ear Nose and Throat, and Turkish Archives of Otorhinolaryngology) in 2016-2020 were analyzed for author self-citations. The association between author self-citations and journal types, study types, study topics, country of origin, and compatibility with the topic were also evaluated.

Results: There were 265 author self-citations ( 0.273 per article) which corresponded to $1.36 \%$ of all citations. There was no significant difference between the journal types, study topics, and origin of the studies in terms of mean self-citation values per study, whereas case reports had significantly lower self-citations than review and original investigations. There were three citations (1.1\%) that were irrelevant to the study topic.

Conclusion: To the best of our knowledge, this is the first study that investigated the practice of author self-citation in Turkish ORL literature. Author self-citation rate in the Turkish-originated general ORL journals was found remarkably lower than the medical literature, whereas the selfcitations were found compatible with the study topic to a very large extent. Members of the scientific community including authors, readers, and journal editors should be cautious regarding the unethical practices of self-citations.

Keywords: Bibliometric analysis, publications, self-citation, otorhinolaryngology, publication ethics.

\section{Introduction}

One of the main goals of publishing a scientific work is to introduce its existence to scientific and public recipients as much as possible which can also be defined as "recognization". It is also anticipated from scientific work to provide a significant impact on medical literature which is also valid for researchers and journals. Hence, every scientific content requires 
objective measurement methods to quantitatively present its impact and recognization. Several bibliographic indicators have been utilized to objectively assess the recognization or impact of research, author or journal such as citations, Hirsch index (H-index), and impact factor with the presence of their limitations (1-3). Although bibliometric significance and accuracy of citations are still a matter of debate, highly cited scientific works are theoretically considered to be more important and influential (4). Therefore, high citation numbers are assumed to be a constant parameter that warrants scientific achievements such as career promotion and academic reputation.

Self-citation is a type of citation that refers to citing one's own work (5). It comprises multiple subtypes that are ascribed for authors, journals, institutions, countries, and languages (6). Self-citations are likely to be an inevitable entity for productive researchers especially focus on a specific field since they have a higher probability to cite their own papers (7). Also, self-citations have multiple benefits since they enable authors to expand earlier hypotheses, refer to the established methodology and utilize them for further investigations (8). However, self-citations can also be manipulated by the researchers to affect their influence and recognization. Due to the potential role of author self-citations in citation manipulation, the accurate utilization of self-citations has become an ethical concern and there is ongoing effort to better delineate the self-citation-based ethical misconducts in the academic era (9-14).

Author self-citation is simply defined as any instance where a given author cites their own articles in subsequent scholarly works (11). The role of author self-citation in different medical specialties including otorhinolaryngology (ORL) has been investigated in the literature $(6-8,15-17)$. However, the prevalence and other characteristics of author selfcitation in Turkish ORL literature are unidentified to date. In the present study, we aimed to evaluate the prevalence and other characteristics of author self-citations in six Turkeyoriginated ORL journals of Turkish ORL literature.

\section{Methods}

The articles from six Turkey-originated general ORL journals (ENT Updates, Journal of Ear Nose Throat and Head Neck Surgery, KBB-Forum, Praxis of Otorhinolaryngology, The Turkish Journal of Ear Nose and Throat, and Turkish Archives of Otorhinolaryngology) published between 2016 and 2020 were evaluated for author self-citations. The studies that belonged to the supplements were not included in the study. The articles were analyzed according to the authors, citations, study topics and types, country of origin, and language. Original investigations, case reports, and reviews were included among the article types. Study topics were categorized as otology, rhinology, head/neck, pediatric
ORL, and general ORL. The total and the mean number of self-citations were calculated per study. Self-citations were evaluated according to the journals, type and topic of the articles, and country of origin. Study authors were categorized as the first author, last author, and other authors, and the mean number of self-citations calculated according to the author arrangement was compared. Additionally, selfcitations were reviewed in terms of compatibility with the issue of the main text to reveal possible manipulations.

Statistical analysis was performed using Statistical Package for the Social Sciences (v. 21; SPSS Inc., IBM Corp., Armonk, NY). Data were tested for normal distribution using the Kolmogorov-Smirnov test. Mann-Whitney U and Kruskal-Wallis tests were used to compare the mean author self-citation values between the journal types, study topics, study types, and study origins. A p-value less than 0.05 was considered significant for all comparisons.

\section{Results}

Characteristics of the published articles and distribution of the self-citations are shown in Table 1 . A total of 970 articles were found in 2016-2020 with the Turkish Archives of Otorhinolaryngology (21.1\%) and The Turkish Journal of Ear Nose and Throat (19.5\%) had the highest number of articles. Of the 970 articles, 287 (29.6\%) were written in Turkish, whereas 683 (70.4\%) were written in English. The most frequent study topics were otology (29.8\%) and general ORL (21.7\%), respectively, whereas original investigations had the highest rate among the study types (75.3\%). There were 909 (93.7\%) Turkey-originated studies, while 61 (6.3\%) were published from foreign countries (Table 2). The mean number of authors and citations per study were 4.3 and 20.1, respectively.

One hundred sixty-eight (17.3\%) articles involved author self-citations. The maximum and minimum numbers of selfcitation for a single article were 11 and one, respectively. The total number of self-citations was 265 with an average number of 0.273 per article. The total number of selfcitations constituted $1.36 \%$ of all citations. Turkish Archives of Otorhinolaryngology and The Turkish Journal of Ear Nose and Throat had the highest mean value of self-citations per study, whereas otology and reviews had the highest mean value of self-citations among the study topics and types, respectively. Case reports involved a significantly lower mean value of self-citations than original reports and reviews $(p<0.001)$. Reviews had also significantly higher mean value of self-citations than original reports. There were no significant differences between the journal types, study topics, and origin of the articles in terms of mean self-citation values per study. There was no significant difference between the first ( $n=90,0.119$ per study), last ( $n=98,0.155$ per study), 
Table 1. Characteristics of the published studies and distribution of the self-citations

\begin{tabular}{|c|c|c|c|c|c|}
\hline & & Number of study (\%) & $\begin{array}{l}\text { Number of self-citation } \\
(\%)\end{array}$ & $\begin{array}{l}\text { Self-citation per } \\
\text { study }\end{array}$ & $\mathrm{p}^{*}$ \\
\hline \multirow{4}{*}{ Journal } & TAO & $205(21.1)$ & $74(27.9)$ & 0.36 & \multirow{4}{*}{0.276} \\
\hline & Tr-ENT & $189(19.5)$ & $54(20.4)$ & 0.285 & \\
\hline & KBB-Forum & $167(17.2)$ & $45(17)$ & 0.269 & \\
\hline & ENT-HNS & $117(12.1)$ & $30(11.3)$ & 0.256 & \\
\hline \multirow[b]{3}{*}{ Study topic } & Otology & $289(29.8)$ & $101(38.1)$ & 0.349 & \multirow[b]{3}{*}{0.083} \\
\hline & General ORL & $210(21.7)$ & $52(19.6)$ & 0.247 & \\
\hline & Head and Neck & $202(20.8)$ & $43(16.2)$ & 0.212 & \\
\hline \multirow[t]{2}{*}{ Study type } & Case Report & $202(20.8)$ & $15(5.7)$ & 0.074 & \multirow[t]{2}{*}{$<0.001$} \\
\hline & Review & $38(3.9)$ & $43(16.2)$ & 0.883 & \\
\hline \multirow{2}{*}{ Country of origin } & Turkey & $909(93.7)$ & $239(90.2)$ & 0.262 & \multirow[t]{2}{*}{0.561} \\
\hline & Foreign countries & $61(6.3)$ & $26(9.8)$ & 0.426 & \\
\hline \multirow{2}{*}{ Total } & Number of study & 970 & 265 & - & \multirow[t]{2}{*}{-} \\
\hline & Number of self-citation & & & & \\
\hline
\end{tabular}

ENT: Ear Nose Throat, ENT-HNS: Journal of Ear Nose Throat and Head Neck Surgery, ORL: Otorhinolaryngology, Tr-ENT: The Turkish Journal of Ear Nose and Throat, TAO: Turkish Archives of Otorhinolaryngology.

*Statistical comparison for self-citation per study values among the parameters

Table 2. Distribution of the studies according to the country of origin

\begin{tabular}{llll}
\hline Country & $\mathbf{n}(\%)$ & Country & $\mathbf{n}(\%)$ \\
\hline Turkey & $909(93.7)$ & Bosnia & $1(0.1)$ \\
\hline India & $19(1.9)$ & Croatia & $1(0.1)$ \\
\hline Malaysia & $6(0.6)$ & Greece & $1(0.1)$ \\
\hline England & $3(0.3)$ & Iran & $1(0.1)$ \\
\hline Pakistan & $3(0.3)$ & Japan & $1(0.1)$ \\
\hline Portugal & $3(0.3)$ & Morocco & $1(0.1)$ \\
\hline Saudi Arabia & $3(0.3)$ & Montenegro & $1(0.1)$ \\
\hline Brazil & $2(0.2)$ & Nepal & $1(0.1)$ \\
\hline Egypt & $2(0.2)$ & New Zealand & $1(0.1)$ \\
\hline Ghana & $2(0.2)$ & Philippines & $1(0.1)$ \\
\hline Italy & $2(0.2)$ & Russia & $1(0.1)$ \\
\hline Serbia & $2(0.2)$ & USA & $1(0.1)$ \\
\hline Spain & $2(0.2)$ & & \\
\hline n: Number of items & & &
\end{tabular}

and other authors ( $n=107,0.158$ per study) in terms of the mean number of self-citations $(\mathrm{p}=0.396)$. There were three citations (1.1\%) which were irrelevant with the study topic.

\section{Discussion}

In the competitive academic world, researchers necessarily endeavor to improve their productivity. Since higher productivity doesn't always mean higher quality, it is also anticipated from the researchers to confirm their productivity with higher impact. To quantitatively reveal their balance of productivity and impact, citations have become one of the major goals of the researchers that are tried to be obtained. As a consequence, a potential risk has arisen which is manipulating the number of citations as a career motivation and self-citations provide a potential microenvironment for the authors to artificially boost their citation-based metrics (18). Bartneck and Kokkelmans (19) demonstrated that $\mathrm{H}$-index can be significantly inflated through self-citations by the authors. In the present study, we found that author self-citation rates were lower than the literature for the studies published in six Turkey-originated ORL journals between 2016 and 2020. Also, the author self-citations were found compatible with the study topic to a very large extent (98.9\%) which may suggest that the author self-citations are not served for unethical purposes in Turkish ORL practice.

Self-citations were reported to constitute $6-20 \%$ of all citations in the medical literature $(8,15)$. In a study 
investigating the author self-citations in the five highestranked journals of ORL, Tolisano et al (17) found that about two-thirds of all articles included at least one self-citation. The authors reported that self-citations represented $10 \%$ of all citations with an average of 2.6 self-citations per article. In the present study, nearly one of the five studies (17.3\%) published in six Turkey-originated general ORL journals involved at least one self-citations, whereas self-citations constituted $1.36 \%$ of all 100 citations. The mean value of self-citations per study was 0.273 which was remarkably lower than the literature (17). Also, there was no significant difference between the author arrangements in terms of selfcitations in the present study. However, Tolisano et al. (17) reported that lead authors and last authors were the frequent self-citers in the ORL field. As primary conductors, it is logical to expect that the first author appears as a leading self-citer among the authors of a scientific paper. On the other hand, since the last authors are usually composed of researchers with more senior academic positions, they may have a higher opportunity for self-citing due to their long track record of publications and expertise. These discrepancies between the present study and the literature can be associated with a number of facts. In Turkish ORL practice, Turkeyoriginated journals mostly constitute the second line for submitting a study and author preferences regarding the journal choice for submission may influence the self-citation characteristics. For instance, due to academic promotion and recognization concerns, more experienced and productive researchers may tend to publish their high-quality scientific works regarding their specified research fields in journals having high impact factor values rather than publishing in Turkey-originated journals. Mishra et al. (20) reported that self-citations are the hallmark of productive and experienced authors specialized in certain medical fields who may have a higher potential for self-citation. Also, recruit researchers may initially prefer Turkey-originated journals during their learning curve of scientific publishing processes and their low self-citation potentials due to the smaller number of previous works and low expertise may diminish the chance for author self-citation. However, these speculations should be verified with further investigations.

The studies investigating the association between author self-citations and the type and topic of the studies revealed conflicting results in the literature. Livas et al. (7) screened six orthodontic journals with the highest impact factor and found that there was no association between self-citation counts and the type and topic of the studies. However, Tolisano et al. (17) reported that original articles had a significantly higher author self-citation rate, whereas no difference was found among the otolaryngological study topics. The authors found that case reports had significantly lower number of self-citations per article when compared with reviews and original investigations. Similarly, in the present study, the author self-citation values were not significantly different among the study topics, whereas the case reports had significantly lower self-citation values than the other study types.

The present study has several limitations. First, we included the articles published in six Turkey-originated general ORL journals between 2016 and 2020 and the results of the present study cannot be generalized for the entire Turkish ORL literature. Secondly, our study primarily intended to offer a general view of the author self-citations in Turkish ORL practice, hence, it does not provide further data regarding the possible causes of the discrepancies with the literature. Nevertheless, we think that similar studies investigating the author self-citation trends in Turkish ORL practice may have vital importance to raise the awareness of the academic community concerning the author bias of self-citation.

\section{Conclusion}

To the best of our knowledge, this is the first study investigated the practice of author self-citation in Turkish ORL literature. In the present study, author self-citation rate in the Turkishoriginated general ORL journals was found remarkably lower than the medical literature, whereas the self-citations were found compatible with the study topic to a very large extent. Although the results of the present study can be interpreted as the authors in Turkish ORL practice do not use self-citations at a level suggesting citation manipulation, members of the scientific community including authors, readers and journal editors should be cautious regarding the unethical practices of self-citations.

Ethics Committee Approval: Bibliometric study.

Informed Consent: Bibliometric study.

Peer-review: Externally peer-reviewed.

Financial Disclosure: The authors declared that this study received no financial support.

\section{References}

1. Bornmann L, Marx W, Gasparyan AY, Kitas GD. Diversity, value and limitations of the journal impact factor and alternative metrics. Rheumatol Int 2012; 32: 1861-7. [Crossref]

2. Dinis-Oliveira RJ. The H-index in life and health sciences: advantages, drawbacks and challenging opportunities. Curr Drug Res Rev 2019; 11: 82-4. [Crossref]

3. Fernández-Guerrero IM, Martín-Sánchez FJ, Burillo-Putze G, Graham CA, Miró Ò. Analysis of the citation of articles published in the European Journal of Emergency Medicine since its foundation. Eur J Emerg Med 2019; 26: 65-70. [Crossref] 
4. Coelho DH, Edelmayer LW, Fenton JE. Citation analysis of otorhinolaryngology journals: follow-up study. J Laryngol Otol 2015; 129: 489-93. [Crossref]

5. Aksnes D. A macro study of self-citation. Scientometrics 2003; 56: 235-46. [Crossref]

6. Bardeesi AM, Jamjoom AA, Algahtani A, Jamjoom A. The impact of country self-citation rate among medical specialties in Saudi Arabia. Cureus 2021; 13: e12487. [Crossref]

7. Livas C, Delli K, Pandis N. Author self-citation in orthodontics is associated with author origin and gender. Prog Orthod 2021; 22: 1. [Crossref]

8. Gami AS, Montori VM, Wilczynski NL, Haynes RB. Author self-citation in the diabetes literature. CMAJ 2004; 170: 1925-7. [Crossref]

9. Mubin O, Arsalan M, Al Mahmud A. Tracking the follow-up of work in progress papers. Scientometrics 2018; 114: 1159-74. [Crossref]

10. Szomszor M, Pendlebury DA, Adams J. How much is too much? The difference between research influence and self-citation excess. Scientometrics 2020; 123: 1119-47. [Crossref]

11. Ioannidis JP. A generalized view of self-citation: direct, co-author, collaborative, and coercive induced self-citation. J Psychosom Res 2015; 78: 7-11. [Crossref]

12. Van Noorden R, Singh Chawla D. Hundreds of extreme selfciting scientists revealed in new database. Nature 2019; 572: 578-9. [Crossref]
13. Sanfilippo F, Tigano S, Morgana A, Murabito P, Astuto M. Selfcitation policies and journal self-citation rate among Critical Care Medicine journals. J Intensive Care 2021; 9: 15. [Crossref]

14. COPE Council. COPE Discussion Document: Citation Manipulation. July 2019. Available at: https://publicationethics. org/files/COPE_DD_A4_Citation_Manipulation_Jul19_ SCREEN_AW2.pdf [Crossref]

15. Kulkarni AV, Aziz B, Shams I, Busse JW. Author self-citation in the general medicine literature. PLoS One 2011; 6: e20885. [Crossref]

16. Swanson EW, Miller DT, Susarla SM, Lopez J, Lough DM, May JW Jr, et al. What effect does self-citation have on bibliometric measures in academic plastic surgery? Ann Plast Surg 2016; 77: 350-3. [Crossref]

17. Tolisano AM, Song SA, Cable BB. Author self-citation in the otolaryngology literature: a pilot study. Otolaryngol Head Neck Surg 2016; 154: 282-6. [Crossref]

18. Aragón AM. A measure for the impact of research. Sci Rep 2013; 3: 1649. [Crossref]

19. Bartneck C, Kokkelmans S. Detecting h-index manipulation through self-citation analysis. Scientometrics 2011; 87: 85-98.

20. Mishra S, Fegley BD, Diesner J, Torvik VI. Self-citation is the hallmark of productive authors, of any gender. PLoS One 2018; 13: e0195773. [Crossref] 